\title{
Pengaruh Hots, Peer Group, Classroom Management, Motivasi Diri Pada Proses Belajar Siswa Sekolah Menengah Atas Jurusan Sosial
}

\author{
I Riza Primahendra', ${ }^{1}$ reddy ${ }^{2}$, Ardian Sopa ${ }^{3}$ \\ ${ }^{1}$ rizaprimahendra@gmail.com \\ 1,2,3Universitas Pelita Harapan
}

\begin{tabular}{ccc}
$\begin{array}{c}\text { Submitted } \\
\text { November 21, 2019 }\end{array}$ & $\begin{array}{c}\text { Revised } \\
\text { June 23, 2020 }\end{array}$ & $\begin{array}{c}\text { Accepted } \\
\text { June 23, 2020 }\end{array}$ \\
\cline { 2 - 3 } & https://dx.doi.org/ 10.17509/jpis.v29i1.21368 & \\
\hline
\end{tabular}

\begin{abstract}
The study is conducted to understand the relation of HOTS (High Order Thinking Skills), peer group, and class-room management to self-motivation; and the relation of self-motivation to learning process of student. The proposition of the study is development of self-motivation through external and internal factors of the student. The internal factor in the study is HOTS, while external factors comprise of peer group and class-room management. Furtherly, developed self-motivation will have significant impact to the learning process. The data of the study was collected from social science student XII class of one private school located in Jakarta. The data was processed by using SmartPLS program. The study findings are learning process is strongly influenced by self-motivation, and self-motivation is influenced by HOTS, peer group, and class-room management. HOTS and peer group gave strong influence and class-room management have less influence.
\end{abstract}

Keywords: HOTS, Peer Group, Classroom Management, Learning Process.

\begin{abstract}
ABSTRAK
Penelitian dilaksanakan untuk mengetahui hubungan HOTS (High Order Thinking Skills), peer group (kelompok teman dekat), dan classroom management (pengelolaan kelas) pada motivasi diri; serta hubungan motivasi diri dan proses belajar siswa. Proposisi penelitian adalah motivasi diri berkembang melalui faktor internal dan eksternal siswa. Faktor internal dalam studi ini adalah HOTS, sementara faktor eksternal terdiri dari peer group dan manajemen kelas. Selanjutnya, motivasi diri yang berkembang akan memiliki pengaruh positif pada proses belajar siswa. Data penelitian diambil dari siswa kelas 12 jurusan sosial dari sekolah menengah swasta di Jakarta dan diolah mempergunakan program SmartPLS. Penelitian menemukan bahwa proses belajar siswa secara kuat dipengaruhi motivasi diri, serta motivasi diri dipengaruhi HOTS, peer group, dan manajemen kelas. HOTS dan peer group memberikan pengaruh besar dan manajemen kelas memberikan pengaruh kecil.
\end{abstract}

Keywords: HOTS, Rekan Kelompok, Manajemen Kelas, Proses Pembelajaran.

\section{PENDAHULUAN}

Pendidikan didefinisikan sebagai usaha sadar dan terencana untuk mewujudkan suasana belajar dan proses pembelajaran agar peserta didik secara aktif mengembangkan potensi dirinya untuk memiliki kekuatan spiritual keagamaan, pengendalian diri, kepribadian, kecerdasan, akhlak mulia, serta keterampilan yang diperlukan dirinya, masyarakat, bangsa dan negara [1]. Beberapa konsep kunci dari definisi Pendidikan adalah: usaha sadar dan 
terencana, peserta didik yang aktif, pengembangan potensi diri. Komitmen pemerintah Indonesia untuk menyediakan akses pendidikan yang berkualitas kepada warga negara diwujudkan melalui berbagai kebijakan dan program seperti wajib belajar sembilan tahun dan kejar paket. Selain itu Pemerintah Indonesia selama beberapa tahun terakhir juga telah mengalokasikan 20\% Anggaran Pendapatan dan Belanja Negara (APBN) untuk Pendidikan.

Tabel 1. Alokasi Dana Pendidikan

\begin{tabular}{llcccc}
\hline Tahun & 2015 & 2016 & 2017 & 2018 & 2019 \\
\hline $\begin{array}{l}\text { Anggaran } \\
\text { Pendidikan }\end{array}$ & $409,1 \mathrm{~T}$ & 419,2 T & 416,1 T & 444,1 T & 492,5 T \\
\hline Distribusi Alokasi & 1. & Pusat: 163,1 T & & \\
2019 & 2. & Transfer ke daerah: 308,4 T & \\
& 3. & Pembiayaan 21 T & & \\
\hline Sasaran Target & 1. & Program Indonesia Pintar: 20,1 juta jiwa \\
2019 & 2. & Bantuan Operasional Sekolah (BOS): 57 juta jiwa \\
& 3. & Pembangunan/rehab sekolah/ruang kelas: 56,1 ribu \\
& 4. & Beasiswa Bidik Misi: 471,8 ribu mahasiswa &
\end{tabular}

Sumber: Data terolah dari (https://www.kemdikbud.go.id/main/tentang-kemdikbud/pagu-apbn)

Namun demikian, skor PISA (Program for International Student Assessment) Indonesia, yang telah diadopsi oleh Kementerian Pendidikan \& Kebudayaan, tidak mengalami perkembangan signifikan dalam kurun waktu 15 tahun, yakni selalu di bawah angka 400. Sementara itu, semua negara Organisation for Economic Cooperation and Development (OECD) punya rata-rata di atas 500 . Skor PISA yang rendah ini berkorelasi pada temuan lanjut PISA, yakni rendahnya kemampuan berpikir aras tinggi atau high order thinking [2], [3].

Besarnya alokasi dana

Pendidikan ternyata tidak diikuti dengan skor PISA sebagaimana diharapkan. Selain faktor-faktor kebijakan, upaya perbaikan perlu memperhatikan bahwa pelajar saat ini termasuk generasi milenial yang memiliki proses belajar yang berbeda dari periode sebelumnya [4].

Peningkatan pembelajaran menjadi komitmen pemerintah. Untuk itu, proses pembelajaran yang bertumpu pada keaktivan pelajar siswa menjadi penting. Untuk mendorong proses belajar siswa, beberapa hal yang perlu diperhatikan.

Pertama, pelajar saat ini masuk dalam kategori generasi milenial memiliki karakteristik yang khusus sehingga membutuhkan pendekatan pembelajaran yang sesuai [4], [5]. Dalam penelitian yang sama diindikasikan keakraban pelajar dengan teknologi informasi dan komunikasi berpengaruh pada proses belajar dan pengelolaan kelas.

Kedua, proses belajar siswa dipengaruhi oleh motivasi pelajar. Pelajar yang mampu menemukan motivasi atau memotivasi diri diindikasikan akan lebih mampu menjalani proses pembelajaran [6], [7]. Terkait dengan dampak motivasi pada prestasi akademis, [8] menegaskan bahwa motivasi diri menunjukkan signifikansi yang kuat pada prestasi akademis. Selain itu motivasi diri sebagai bagian dari kecerdasan emosional turut berkontribusi dalam 
mengembangkan

ketahanan

(resiliency) siswa dalam proses studi [9]. Sumber motivasi dapat berasal dari dalam diri pelajar dalam bentuk motivasi diri maupun dari luar seperti dari teman sebaya (peer group) maupun dari kegiatan dalam kelas [10], [11]. Pada penelitian lain menyatakan bahwa periode awal kedewasaan, dinamika pembelajaran mengalami perubahan. Pelajar memiliki sikap independen yang lebih besar, serta pengaruh pengajar dan teman dekat berubah. Peran pengajar menurun, sebaliknya peran teman dekat meningkat [12].

Ketiga, pendidikan pada abad 21 menuntut pemikiran aras tinggi dan karenanya Pendidikan perlu disesuaikan agar pelajar dapat mencapai level berpikir yang diharapkan. Kebutuhan menerapkan HOTS juga diperlukan untuk ilmu sosial, termasuk Bahasa [13].

Keempat, perkembangan jaman membuat pengelolaan kelas yang mencakup relasi pengajar dan pelajar menghadapi tantangan besar. Sebagaimana diindikasikan [2] tantangan yang dihadapi pengajar saat ini adalah perilaku yang berubah dari para pelajar. Intervensi yang sebelumnya dapat dipergunakan menjadi tidak lagi memadai. Dibutuhkan kombinasi intervensi pengajar termasuk memberikan umpan balik atas kinerja pelajar secara terus menerus [14]. Memperhatikan hal-hal yang disampaikan diatas, penelitian ini bermaksud untuk mengetahui kaitan antara berbagai faktor yang berpengaruh pada proses belajar siswa, secara khusus motivasi diri, high order thinking style (HOTS), peer group, kemampuan berpikir kritis, logis, reflektif, metakognitif, dan berpikir kreatif yang merupakan kemampuan berpikir tingkat tinggi dan pengelolaan kelas (classroom management).

\section{KAJIAN LITERATUR}

Higher Order of Thinking Skill (HOTS) atau kemampuan berpikir tingkat tinggi merupakan suatu kemampuan berpikir yang tidak hanya membutuhkan kemampuan mengingat saja, namun membutuhkan kemampuan lain yang lebih tinggi, seperti kemampuan berpikir kreatif dan kritis [15]. Pemberian materi Sains disesuaikan dengan hakikatnya yaitu sebagai produk, proses, dan sikap ilmiah, sehingga diharapkan akan terbentuk juga sikap ilmiah pada siswa Penerapan beberapa model pembelajaran seperti pembelajaran berbasis proyek, pembelajaran berbasis masalah, belajar penemuan menjadi peluang bagi guru untuk menerapkan kegiatan pembelajaran pada level HOTS.

Variabel independent dalam penelitian ini adalah HOTS, peer group, dan pengelolaan kelas. Model penelitian yang menggambarkan hubungan antar variabel tersebut dapat dilihat pada Gambar 2. Berdasarkan model penelitian tersebut, maka rumusan hipotesis yang diajukan dalam penelitian ini adalah sebagai berikut:

$\mathrm{H} 1$ : $\quad$ Semakin tinggi motivasi diri (SM) maka proses belajar siswa (KS) akan semakin baik.

$\mathrm{H} 2$ : Semakin tinggi high order thinking skills (HO) maka motivasi diri (SM) akan meningkat.

H3: Semakin kuat peer group (PG) maka motivasi diri (SM)akan meningkat $\mathrm{H}_{4}$ : Semakin baik pengelolaan kelas maka motivasi diri (SM) akan meningkat. Berdasar hipotesa yang dikembangkan, maka tujuan penelitian adalah untuk mengetahui pengaruh HOTS, peer group, dan manajemen kelas pada proses belajar siswa dengan mediasi motivasi diri siswa kelas 12 IPS pada sekolah swasta di Jakarta Barat. 


\section{Gambar 2. Model Penelitian}

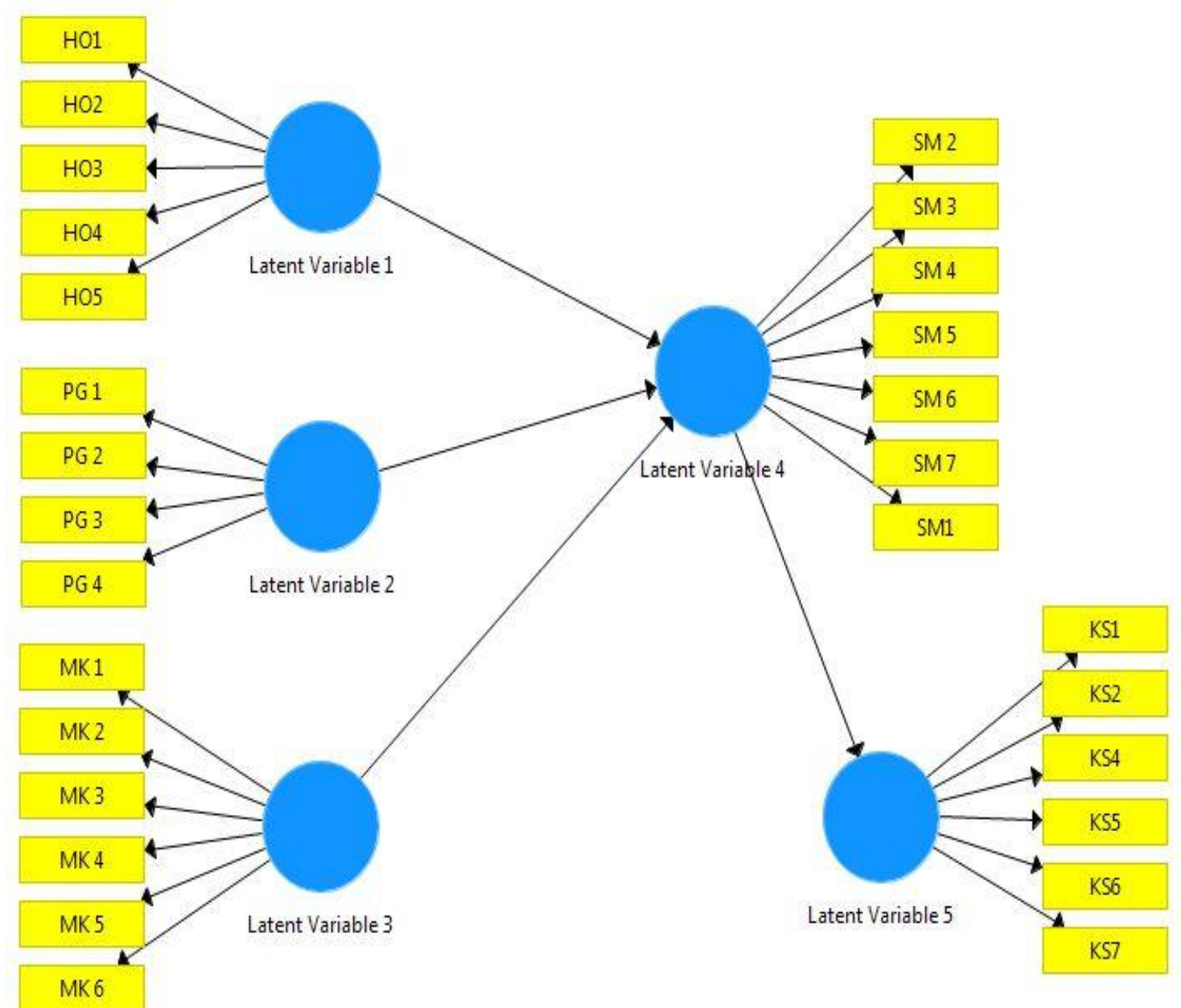

\section{METODE PENELITIAN}

Pengertian Metode penelitian adalah langkah yang dimiliki dan dilakukan oleh peneliti dalam rangka untuk mengumpulkan informasi atau data serta melakukan investigasi pada data yang telah didapatkan tersebut Penelitian ini mempergunakan metode survei dengan pendekatan structural equation modelling. Pengumpulan data dilakukan dengan mengedarkan angket kepada seluruh siswa jurusan IPS yang berada di kelas. Angket disusun secara tertutup dan berisi pernyataan tertutup dengan lima opsi jawaban: sangat setuju atau sesuai skor 5 , setuju atau sesuai skor 4, belum yakin skor 3, tidak Setuju atau tidak sesuai skor 2 , dan sangat tidak setuju atau tidak sesuai skor 1 .
Populasi penelitian adalah seluruh siswa jurusan IPS kelas XII yang berada di kelas pada saat pengumpulan data. Populasi berjumlah 54 dan sekaligus merupakan sampel. Dengan demikian penelitian ini dapat disebut penelitian survey sensus atau sampel jenuh [16].

Metode analisis data dengan mempergunakan alat bantu piranti lunak SmartPLS versi 3.2.8. Sebagaimana dijelaskan [17] PLS (partial least square) adalah metode analisis yang bersifat soft modeling karena tidak membutuhkan data harus dengan jumlah besar. Data dibawah 100 sudah memadai untuk dilakukan analisis. 
HASIL DAN PEMBAHASAN

Hasil estimasi model PLS adalah sebagai berikut:

\section{Gambar 3. Hasil Estimasi Model PLS}

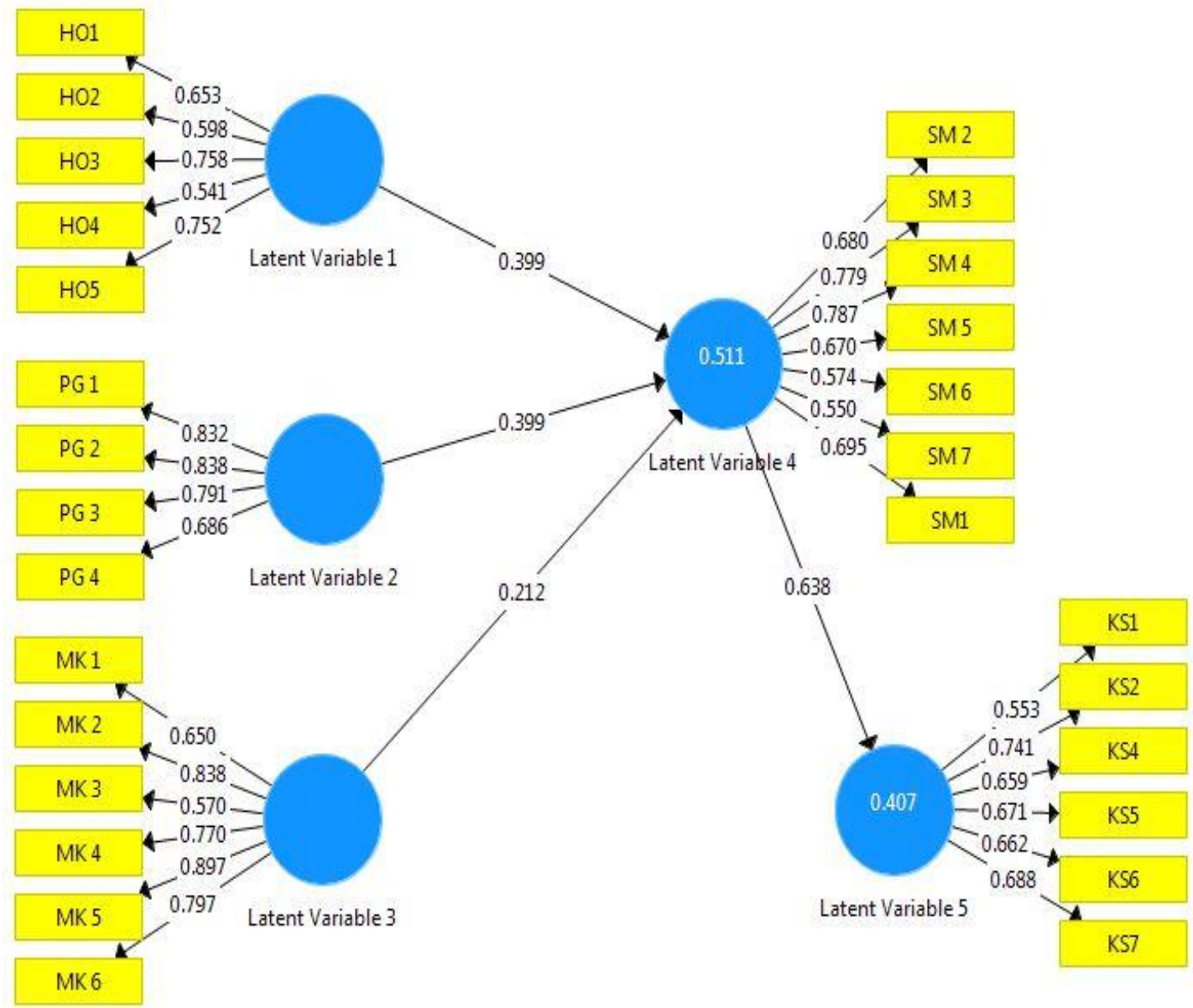

Hasil estimasi model PLS pada gambar 3 menunjukkan seluruh indikator memiliki nilai loading factor di atas 0,5 sehingga model telah memenuhi syarat validitas konvergen. Indikator dengan loading factor lebih besar dari 0,5 berarti memiliki kontribusi yang tinggi untuk menjelaskan konstruk latennya [18].

Untuk memastikan reliabilitas instrumen penelitian maka perlu dilakukan uji composite reliability dan Cronbach Alpha. Konstruk dinyatakan reliabel jika nilai kedua uji diatas 0,70 [19]. Hasil pengujian memperlihatkan hasil sebagai berikut.
Tabel 1. Uji Reliabilitas

\begin{tabular}{|c|c|c|c|c|c|}
\hline \multicolumn{2}{|c|}{ Variabel } & \multicolumn{2}{|c|}{$\begin{array}{l}\text { Cronbach } \\
\text { Alpha }\end{array}$} & \multicolumn{2}{|c|}{$\begin{array}{l}\text { Composite } \\
\text { Reliability }\end{array}$} \\
\hline & TS (HO) & & 0,711 & \multicolumn{2}{|c|}{0,797} \\
\hline & $\begin{array}{l}\text { r Group } \\
\text { (PG) }\end{array}$ & & 0,843 & \multicolumn{2}{|c|}{0,868} \\
\hline $\begin{array}{r}C l \\
M a\end{array}$ & $\begin{array}{l}\text { ssroom } \\
\text { agement } \\
\text { (MK) }\end{array}$ & & 0,917 & \multicolumn{2}{|c|}{0,890} \\
\hline & $\begin{array}{l}\text { Self- } \\
\text { tivation } \\
\text { (SM) }\end{array}$ & & 0,829 & \multicolumn{2}{|c|}{0,857} \\
\hline & $\begin{array}{l}\text { roses } \\
\text { ijar (KS) }\end{array}$ & & 0,763 & \multicolumn{2}{|c|}{0,825} \\
\hline \multicolumn{6}{|c|}{ Tabel 2. Uji Discriminant Validity } \\
\hline & HO & PG & MK & SM & KS \\
\hline HO & 0,666 & & & & \\
\hline PG & 0,252 & 0,789 & & & \\
\hline MK & 0,145 & 0,251 & 0,762 & & \\
\hline SM & 0,531 & 0,553 & 0,370 & 0,682 & \\
\hline KS & 0,395 & 0,553 & 0,402 & 0,638 & 0,665 \\
\hline
\end{tabular}


Hasil diatas memperlihatkan penelitian telah memenuhi kriteria Fornell-Larcker.

Hasil estimasi model PLS memperlihatkan R-squared untuk motivasi diri sebesar 0,511 yang berarti ketiga variabel berkontribusi menjelaskan motivasi diri sebesar 51,1\% sementara motivasi diri berkontribusi menjelaskan proses belajar siswa sebesar 40,7\%. Hal ini sesuai dengan kesimpulan penelitian [8]. Motivasi diri berpengaruh besar pada proses belajar siswa dengan karakteristik usia 17-19 tahun dan bertempat tinggal di Jakarta. Hasil ini mengindikasikan tanpa motivasi diri maka siswa tidak akan mampu melaksanakan proses belajar secara optimal.

Penelitian ini juga memperlihatkan bahwa kontribusi HOTS pada motivasi diri sama dengan peer group, sebaliknya manajemen kelas berkontribusi lebih kecil. Hal ini selaras dengan penelitian [13], [20] Dengan demikian dapat dikatakan bahwa HOTS dan peer group adalah variabel yang berpengaruh pada motivasi diri dengan HOTS selaku variabel internal dan peer group sebagai variabel eksternal. Dengan demikian dapat dirumuskan bahwa kemampuan berpikir aras tinggi (HOTS) merupakan skill yang relevan dan penting bagi siswa generasi milenial. Demikian pula peer group menjadi faktor positif yang mendukung proses belajar siswa melalui mediasi motivasi diri.

Penelitian ini juga menegaskan tantangan yang dihadapi pengajar-siswa dalam ruang kelas sebagaimana disimpulkan dalam penelitian [2]. Tiga hal yang dapat menjadi sebab kegiatan dalam kelas memberikan kontribusi yang tidak sebesar HOTS dan peer group pada motivasi diri siswa, yaitu: karakteristik siswa saat ini yang berbeda dari generasi sebelumnya, strategi pengajaran yang belum disesuaikan dengan karakteristik siswa, peningkatan kapasitas guru untuk berproses bersama siswa milenial.

\section{SIMPULAN}

Peneitian yang dilakukan telah menghasilkan beberapa kesimpulan bahwa proses belajar siswa dipengaruhi oleh motivasi diri siswa. Siswa yang mampu mengembangkan motivasi diri berpotensi mampu mengembangkan proses belajar yang positif, Motivasi diri siswa lebih dipengaruhi oleh HOTS dan peer group. Siswa yang memiliki skill berpikir aras tinggi dan peer group yang sesuai cenderung mampu mengembangkan motivasi diri yang lebih baik, Pengelolaan kelas masih memiliki pegaruh positif pada motivasi diri siswa namun ditantang untuk dikelola lebih baik agar menjadi lebih relevan bagi siswa milenial.

Penelitian ini mengambil sampel yang cukup spesifik yaitu siswa kelas XII di sekolah swasta berlokasi di Jakarta Barat. Diperlukan penelitian lanjutan untuk memperluas sampel dan wilayah. Selain itu peran keluarga juga perlu menjadi variabel yang diperhitungkan.

\section{REKOMENDASI}

Sehubungan dengan penelitian ini yang telah dilaksanakan memiliki tekerbatasan mengambil subjek, materi yang sangat spesifik dan metode yang sangat sederhana. Maka peneliti menyarankan kepeda pihak lain untuk melakukan penelitian lanjutan dikenakan pada subjek yang lebih luas materi yang lebih umum dan metode yang lebih relevan sehingga dapat memunculkan hasil penelitian yang lebih baik. 
DAFTAR PUSTAKA

[1] U.-U. R. INDONESIA and N. 20 T. 2003, TENTANG SISTEM PENDIDIKAN NASIONAL. 2003.

[2] M. Collier-Meek, "Barriers to implementing classroom management and behavior support plans," An Explor. Investig. Wiley, 2018.

[3] N. Isnawati, D. Samian, A. Prodi Pendidikan Akuntansi FKIP-UMS, and D. Prodi Pendidikan Akuntansi FKIP -UMS, "Kemandirian Belajar Ditinjau Dari Kreativitas Belajar Dan Motivasi Belajar Mahasiswa," Journals.Ums.Ac.Id, vol. 1, pp.128144, 2010.

[4] A. Alexander, "Understanding and meeting the needs of the millennials in the classroom," $A$ Lit. Rev. UNI Sch., 2012.

[5] Suranto, "Pengaruh Motivasi, Suasana Lingkungan dan Sarana Prasarana Belajar terhadap Prestasi Belajar Siswa (Studi Kasus pada SMA Khusus Putri SMA Islam Diponegoro Surakarta)," J. Pendidik. Ilmu Sos., vol. 25, no. 2, pp. 11-19, 2015.

[6] L. J. Bailey, Thomas Hamilton, Phillips, The influence of motivation and adaptation on students' subjective well-being, meaning in life and academic performance. 2015.

[7] T. R. Rohana, "Kontribusi Motivasi Belajar, Perilaku Prososial Dalam Ips, Dan Lingkungan Keluarga Terhadap Penguatan Modal Sosial Peserta Didik," J. Pendidik. Ilmu Sos., vol. 25, no. 2, p. 172, 2017.

[8] A. Yahaya, "The Impact of Emotional Intelligence Element on Academic Achievement," Arch. Des Sci., 2012.
[9] D. H. Di Fabio, Annamaria, Saklofskeb, "The contributions of personality and emotional intelligence to resiliency," Elsevier, 2018.

[10] T. R. Rohana, "Kontribusi Motivasi Belajar, Perilaku Prososial dalam IPS, dan Lingkungan Keluarga terhadap Penguatan Modal Sosial Peserta Didik," J. Pendidik. Ilmu Sos., vol. 25, no. 2, pp. 172-181, 2016.

[11] E. R. Rosilah, "Meningkatkan Hasil Belajar Siswa Kelas IV di SDN Babakan Tarogong 5 Bandung pada Pembelajaran IPS melalui Strategi Pembelajaran Pemecahan Masalah," J. Pendidik. Ilmu Sos., vol. 25, no. 2, pp. 207212, 2016.

[12] M. C. Engels, "Behavioral Engagement, Peer Status, and Teacher-Student Relationships in Adolescence," J. Youth Adolesc., 2016.

[13] A. R. Jamian, "High-Order Thinking Skill (HOTS) of the Students in Aspect of Understanding Modern Poetry and Prose of Malay Language," IJARBSS, 2018.

[14] A. Aritzeta, "Classroom emotional intelligence and its relationship with school performance," Elsevier, 2015.

[15] M. Holilah, "Kearifan Ekologis Budaya Lokal Masyarakat Adat Cigugur Sebagai Sumber Belajar Ips," J. Pendidik. IImu Sos., vol. 24, no. 2, pp. 163-178, 2016.

[16] Sugiyono, Metode Penelitian Kuantitatif dan Kualitatif. Bandung: Alfabeta, 2014.

[17] I. Ghozali, Structural Equation Modeling, Metode Alternatif dengan Partial Least Square. Semarang: Universitas 
Diponegoro, 2014.

[18] J. F. Hair, Multivariate Data Analysis. New York: Prentice Hall International, 2010.

[19] I. Ghozali, Structural Equation Modelling. Semarang: Universitas Diponegoro, 2008.
[20] D. Safitri, "The Effects of Higher Order Thinking (HOT) Laboratory Design in Hooke Law on Student's Creative Thinking Skills," J. Phys., 2019. 